\title{
Adenoid cystic carcinoma of the breast in the United States (1977 to 2006): a population-based cohort study
}

\author{
Bassam Ghabach ${ }^{1,2^{*}}$, William F Anderson ${ }^{3}$, Rochelle E Curtis ${ }^{3}$, Mark M Huycke ${ }^{1,2}$, Jackie A Lavigne ${ }^{3}$, \\ Graça M Dores ${ }^{1,3}$
}

\begin{abstract}
Introduction: Adenoid cystic carcinoma of the breast (breast-ACC) is a rare and special type of basal-like tumor for which scant population-based descriptive data exist. We sought to provide new population-based information on breast-ACC incidence, relative survival, and associated cancer risk in the United States.

Methods: Using data from the Surveillance, Epidemiology and End Results Program, we calculated age-adjusted incidence rates (IRs), IR ratios (IRRs), and relative survival for breast-ACC, and standardized incidence ratios (SIRs) for other cancers.

Results: Overall 338 women ( $I R=0.92 / 1$ million person-years) were diagnosed with breast-ACC during 1977 to 2006. Blacks had 39\% lower IRs than Whites (IRR $=0.61,95 \%$ confidence interval $=0.37$ to 0.96 ), and IRs remained constant over the 30-year period. Ninety-five percent of cases presented with localized stage $(n=320 ; \mathbb{R}=0.87$ ), and the highest IRs were observed for estrogen receptor (ER)-negative/progesterone receptor (PR)-negative tumors $(I R=0.56)$. Like other typically ER-negative tumors, age-specific IRs increased until midlife and then plateaued. Fiveyear, 10-year, and 15-year relative survival was $98.1 \%, 94.9 \%$, and $91.4 \%$, respectively. The risk of female breast cancer was not increased following $(S I R=0.89,95 \%$ confidence interval $=0.43$ to 1.64$)$ or preceding $(S I R=0.71$, $95 \%$ confidence interval $=0.28$ to 1.46) breast-ACC. Similarly, no association was observed for breast-ACC and risk of all other cancers combined, solid tumors, or lymphohematopoietic malignancies.
\end{abstract}

Conclusions: Breast-ACC among women is characterized by ER-negative/PR-negative expression, rare regional lymph node involvement, a favorable prognosis with excellent survival, and absence of associated cancers. These findings reinforce the importance of tailored treatments for breast-ACC and lend credence to the apparent heterogeneity of basal-like breast cancers.

\section{Introduction}

Adenoid cystic carcinoma (ACC) of the breast (breastACC) is a rare basal-like breast cancer [1-3]. Previously termed cylindroma, ACC was initially described by Billroth in 1856 [4] - with the first description of breastACC credited to Geschickter in 1945 [5]. The term cylindroma is now used exclusively to describe benign appendageal tumors of the skin. The morphologic appearance of breast-ACC is similar to ACC occurring at other organ sites, including the salivary gland, lung,

\footnotetext{
* Correspondence: bassam-ghabach@ouhsc.edu

'Department of Veterans Affairs Medical Center, Medical Service (111), 921 NE 13th Street, Oklahoma City, OK 73104, USA
}

and skin [1,6-13]. The diagnostic criteria for breast-ACC includes the presence of a biphasic cellular pattern of myoepithelial and epithelial cells (basaloid and ductal) $[1,6,14,15]$. True to the molecular signature of basal-like tumors $[2,3,16]$, breast-ACC is often estrogen receptor (ER)-negative and progesterone receptor (PR)-negative [17-20] and does not express HER-2-neu [18,20,21]. Clinical studies suggest that breast-ACC is associated with a favorable survival [22-25], thus belying the expected poor prognosis suggested by the absence of hormone receptor expression.

While the epidemiology of other special breast cancer types, including medullary and papillary carcinomas, has

\section{() Biomed Central}


been described in population-based studies [26], most information on breast-ACC is derived from case reports and clinical series - with the largest series reporting fewer than 40 cases [22-24,27] - including one population-based study [28]. Reports of breast-ACC have originated from Europe, North America, Australia, and Asia, with the majority describing a female predominance [14,21,23,24,27-39]. Information on race and ethnicity is sparse, and it is uncertain whether a racial predilection exists for breast-ACC $[35,40]$. In addition, synchronous and metachronous breast tumors and nonbreast tumors occurring with breast-ACC have been described $[14,23-25,27,28,32,41,42]$, but the risk of associated cancers has not been quantified. To gain insight into the epidemiologic features of breast-ACC, we undertook a population-based study in the Surveillance, Epidemiology and End Results (SEER) Program to provide new information on incidence, relative survival, and associated cancer risk.

\section{Materials and methods}

We utilized data from nine cancer registry areas of the SEER Program (SEER-9) that represent approximately $10 \%$ of the population in the United States. SEER-9 includes the states of Connecticut, Hawaii, Iowa, New Mexico, and Utah and the areas of Detroit in Michigan, San Francisco in California, Atlanta in Georgia, and Seattle (Puget Sound) in Washington. These nine areas include a racially diverse population representing approximately 9\% Whites, 9\% Blacks, 13\% American Indians/Alaskan Natives, $19 \%$ Asians, $46 \%$ Native Hawaiians/Pacific Islanders, and $8 \%$ of other races in the United States [43].

The SEER Program classifies histology and topography information according to the third edition of the International Classification of Diseases for Oncology [44]. We included all cases of microscopically confirmed, invasive (behavior code of/3) ACC (M8200) of the breast (C500509) diagnosed during 1977 to 2006.

\section{Incidence}

We calculated incidence rates (IRs), IR ratios (IRRs), and 95\% confidence intervals (CIs) using the Rate Session in the SEER*Stat software (version 6.5.2; Surveillance Research Program, National Cancer Institute, Bethesda, Maryland, USA) [3]. Incidence rates were age-adjusted to the 2000 US standard population and are expressed per 1 million person-years.

Among females diagnosed with breast-ACC during 1977 to 2006, we assessed IRs according to race (White, Black, other/unspecified), calendar period (1977 to 1986, 1987 to 1996,1997 to 2006$)$, age ( $<50, \geq 50$ years), laterality (right, left, bilateral, unspecified), quadrant (upper inner quadrant (C50.2), lower inner quadrant (C50.3), lower outer quadrant (C50.5), upper outer quadrant (C50.4, C50.6), central/nipple (C50.0-50.1), overlapping (C50.8), not specified (C50.9)), SEER stage (localized, regional, distant, unstaged), and grade (low grade, including grades I and II; high grade, including grade III and IV; unknown). Localized stage includes tumors confined to breast tissue or fat, including nipple and areola (but not skin); regional stage includes tumors that directly extend to local structures (for example, skin, chest wall, muscle, ribs) and/or local lymph nodes (LNs) (for example, axillary, internal mammary); and distant stage includes tumors that have spread to distant organs (for example, bone, lung, adrenal) or distant LNs (for example, cervical, supraclavicular, contralateral axillary/ internal mammary). Excluding inflammatory carcinoma, the major change in SEER staging over the study period was that beginning in 2000 infraclavicular LN involvement was considered regional stage whereas it had previously been classified as distant stage.

Information on tumor size and regional LN involvement was not collected in the SEER Program until 1988, and data on ER and PR status did not become available until 1990. We therefore limited analyses of tumor size $(\leq 2 \mathrm{~cm},>2 \mathrm{~cm}$, unspecified) and LN status (negative, positive, unspecified) to cases diagnosed during 1988 to 2006, and limited analyses of ER (positive, negative, other/unspecified) and PR (positive, negative, other/ unspecified) to breast-ACC diagnosed during 1990 to 2006. Treatment information in the SEER Program is limited to that received with the initial cancer diagnosis (surgery, radiation therapy), and data on subsequent therapy are not collected. Information on chemotherapy and hormonal therapy is not available in the SEER Public Use Database.

Age-specific IRs were calculated according to eight age groups ( $<15$ years, 15 to 24 years, 25 to 34 years, 35 to 44 years, 45 to 54 years, 55 to 64 years, 65 to 74 years, $\geq 75$ years) and depicted on a log-linear scale as previously described [45]. For the purpose of comparison, we calculated age-specific IRs for other microscopically confirmed special types of female breast cancer, including lobular (M8520), mucinous (M8480), tubular (M8211), medullary (M8510), and papillary (M8050, $8260,8503)$ carcinomas. According to the SEER Program convention, incidence rates were not calculated for fewer than 16 cases [46].

\section{Multiple primary cancers}

We assessed the risk of subsequent cancer among 2month survivors of breast-ACC and the risk of subsequent breast-ACC among more than 1.2 million 2-month survivors of all cancers diagnosed between 1 January 1977 and 31 December 2006 using the standardized incidence ratio (SIR) session in the SEER*Stat 
software. Analyses of multiple primary cancers were limited to females because of the rare occurrence of breastACC among males. SIRs or observed-to-expected number of subsequent cancers and exact $95 \%$ CIs were calculated by compiling person-years of observation according to age, gender, race, and calendar period beginning 2 months after the diagnosis of cancer to the study end date, date of death, or date of last known follow-up, whichever occurred first. The expected number of subsequent cancers was estimated by calculating cancer IRs according to gender, race, 5-year age groups, and 5-year calendar periods and then multiplying by the person-years at risk.

\section{Survival}

Using the SEER*Stat Survival Session, we estimated 5-year, 10 -year, and 15-year relative survival of breast-ACC and 95\% CIs using the actuarial method. We included all cases of microscopically confirmed, invasive breast-ACC among women with known age who were diagnosed in SEER-9 during 1977 to 2005 and were actively followed for vital status through 2006. We excluded cases diagnosed among individuals with second or later primary cancers $(n=34)$. There were no cases of breast-ACC diagnosed by death certificate or autopsy, with invalid vital status or dates, or with unknown survival time. Survival rates were not calculated for fewer than 25 cases [46].

\section{Results}

Overall 338 women ( $\mathrm{IR}=0.92 / 1$ million person-years) (Table 1) and five men were diagnosed with breast-ACC during 1977 to 2006. Owing to the small number of cases among men, further analyses were restricted to women. Mean and median ages at diagnosis were 63 years and 62 years (range 33 to 97 years), respectively, among women. The majority of cases were diagnosed among White women, and Black women had 39\% significantly lower IRs than Whites (IRR $=0.61,95 \% \mathrm{CI}=0.37$ to 0.96 ). IRs of breast-ACC did not change appreciably over the 30year study period. Women aged 50 years or older had an 11 -fold higher incidence of breast-ACC than younger women (IRR $=11.02,95 \% \mathrm{CI}=8.31$ to 14.87 ). Rates did not differ by left-sided or right-sided laterality $(I R R=$ $1.06,95 \% \mathrm{CI}=0.85$ to 1.32 ), and there were no cases of bilateral breast-ACC. Most cancers occurred in the upper outer quadrants, with more than $70 \%$ lower IRs for breast-ACC occurring in each of the other quadrants. Ninety-five percent of cases presented at localized stage ( $n=320 ; \mathrm{IR}=0.87)$, with regional and distant disease reported rarely. Thirty percent of women $(n=102)$ were treated with radiation as part of initial therapy for breastACC, whereas the remaining $70 \%(n=236)$ were not.
Table 1 Age-adjusted female adenoid cystic carcinoma of the breast incidence rates and incidence rate ratios

\begin{tabular}{|c|c|c|c|c|}
\hline \multirow[b]{2}{*}{ Characteristic } & \multicolumn{4}{|c|}{ Total } \\
\hline & $n$ & IR & IRR & $95 \% \mathrm{Cl}$ \\
\hline Total & 338 & 0.92 & NA & \\
\hline \multicolumn{5}{|l|}{ Race } \\
\hline Whites & 295 & 0.97 & 1.00 & Reference \\
\hline Blacks & 20 & 0.59 & 0.61 & 0.37 to 0.96 \\
\hline Other/unspecified & 23 & $\sim$ & $\sim$ & $\sim$ \\
\hline \multicolumn{5}{|l|}{ Calendar period } \\
\hline 1977 to 1986 & 79 & 0.78 & 1.00 & Reference \\
\hline 1987 to 1996 & 121 & 1.02 & 1.30 & 0.97 to 1.76 \\
\hline 1997 to 2006 & 138 & 0.96 & 1.23 & 0.93 to 1.65 \\
\hline \multicolumn{5}{|l|}{ Age } \\
\hline$<50$ years & 59 & 0.25 & 1.00 & Reference \\
\hline$\geq 50$ years & 279 & 2.70 & 11.02 & 8.31 to 14.87 \\
\hline \multicolumn{5}{|l|}{ Laterality } \\
\hline Right & 164 & 0.45 & 1.00 & Reference \\
\hline Left & 173 & 0.47 & 1.06 & 0.85 to 1.32 \\
\hline Not specified & 1 & $\sim$ & $\sim$ & $\sim$ \\
\hline \multicolumn{5}{|l|}{ Site } \\
\hline Upper outer quadrant & 105 & 0.29 & 1.00 & Reference \\
\hline Upper inner quadrant & 29 & 0.08 & 0.28 & 0.18 to 0.43 \\
\hline Lower outer quadrant & 23 & 0.06 & 0.22 & 0.13 to 0.35 \\
\hline Lower inner quadrant & 14 & $\sim$ & $\sim$ & $\sim$ \\
\hline Nipple/central & 28 & 0.08 & 0.27 & 0.17 to 0.41 \\
\hline Overlapping & 89 & 0.24 & 0.83 & 0.62 to 1.11 \\
\hline Not specified & 50 & 0.14 & 0.47 & 0.33 to 0.67 \\
\hline \multicolumn{5}{|l|}{ Stage } \\
\hline Localized & 320 & 0.87 & 1.00 & Reference \\
\hline Regional & 14 & $\sim$ & $\sim$ & $\sim$ \\
\hline Distant & 1 & $\sim$ & $\sim$ & $\sim$ \\
\hline Unstaged & 3 & $\sim$ & $\sim$ & $\sim$ \\
\hline \multicolumn{5}{|l|}{ LN and size $\mathrm{e}^{\mathrm{a}}$} \\
\hline LN negative, $\leq 2 \mathrm{~cm}$ & 126 & 0.50 & 1.00 & Reference \\
\hline LN negative, $>2 \mathrm{~cm}$ & 67 & 0.26 & 0.52 & 0.38 to 0.71 \\
\hline LN positive, $\leq 2 \mathrm{~cm}$ & 2 & $\sim$ & $\sim$ & $\sim$ \\
\hline LN positive, $>2 \mathrm{~cm}$ & 3 & $\sim$ & $\sim$ & $\sim$ \\
\hline Other/not specified & 46 & 0.18 & 0.36 & 0.25 to 0.51 \\
\hline \multicolumn{5}{|l|}{ Hormone receptors ${ }^{\mathrm{b}}$} \\
\hline ER-negative/PR-negative & 128 & 0.56 & 1.00 & Reference \\
\hline ER-negative/PR-positive & 6 & $\sim$ & $\sim$ & $\sim$ \\
\hline ER-positive/PR-positive & 21 & 0.09 & 0.16 & 0.10 to 0.25 \\
\hline ER-positive/PR-negative & 12 & $\sim$ & $\sim$ & $\sim$ \\
\hline Other/not specified & 55 & 0.24 & 0.42 & 0.30 to 0.59 \\
\hline
\end{tabular}

Data from the nine cancer registry areas of the Surveillance, Epidemiology and End Results Program, 1977 to 2006. Incidence rates are age-adjusted to the 2000 US standard population and are expressed per 1 million personyears. Incidence rate ratios are based on unrounded rates. $n$, number of cases; IR, incidence rate; IRR, incidence rate ratio; $\mathrm{Cl}$, confidence interval; $\mathrm{NA}$, not applicable; , IRs and IRRs not calculated for fewer than 16 cases or other/ unspecified race; LN, regional lymph nodes; ER, estrogen receptor; PR, progesterone receptor. ${ }^{a}$ Limited to cases with localized/regional stage diagnosed in 1988 or later. 'bimited to cases diagnosed in 1990 or later. 
The mean and median tumor size among women diagnosed in 1988 or later was $2.1 \mathrm{~cm}$ and $1.8 \mathrm{~cm}$ (range 0.1 to $16.0 \mathrm{~cm} ; n=229$ ), respectively. The tumor size was unspecified for $7 \%$ of women $(n=18)$. Most women with localized and regional stage breast-ACC had uninvolved LN, with $48 \%$ significantly lower incidence of tumors $>2 \mathrm{~cm}$ compared with smaller tumors (IRR $=0.52,95 \% \mathrm{CI}=0.38$ to 0.71$)$. Grade was not specified for $61 \%$ of cases $(n=207)$, thereby limiting further analysis. The majority of female breast-ACC were ER-negative/PR-negative ( $\mathrm{IR}=0.56, n=128$ ).

Breast-ACC age-specific IRs increased prominently beginning at ages 35 to 44 years, with a less marked rise in incidence at older ages and an apparent plateau beginning at ages 55 to 64 years (Figure 1). A similar pattern was noted for medullary breast cancer $(n=$ $5,973, \mathrm{IR}=16.62$ ), with the exception that IRs decreased more prominently among the oldest age group $(\geq 75$ years). In contrast, papillary $(n=2,902, \mathrm{IR}=7.72)$ and mucinous $(n=10,404$, IR $=27.73)$ female breast cancer IRs increased exponentially with advancing age. Lobular $(n=34,048, \mathrm{IR}=92.52)$ and tubular $(n=5,833$, IR $=$ 16.07) carcinomas were characterized by an intermediate
Table 2 Standardized incidence ratios of subsequent cancer among 2-month female survivors of first primary breast-ACC

\begin{tabular}{llll}
\hline Subsequent cancer $^{\mathbf{a}}$ & Obs. & SIR & $\mathbf{9 5 \%} \mathbf{C l}$ \\
\hline All cancers, excluding nonmelanoma skin & 40 & 1.01 & 0.72 to 1.38 \\
All solid cancers & 33 & 0.94 & 0.65 to 1.32 \\
$\quad$ Colon and rectum & 8 & 1.43 & 0.62 to 2.81 \\
$\quad$ Lung and bronchus & 7 & 1.24 & 0.50 to 2.55 \\
$\quad$ Female breast & 10 & 0.89 & 0.43 to 1.64 \\
$\quad$ Uterine corpus & 3 & 1.27 & 0.26 to 3.72 \\
All lymphohematopoietic cancers & 6 & 1.86 & 0.68 to 4.05 \\
$\quad$ Non-Hodgkin lymphoma & 4 & 2.44 & 0.66 to 6.24 \\
$\quad$ Acute myeloid leukemia & 2 & 7.24 & 0.88 to 26.16
\end{tabular}

Data from the nine cancer registry areas of the Surveillance, Epidemiology and End Results Program, 1977 to 2006. Breast-ACC, adenoid cystic carcinoma of the breast; Obs., observed number of subsequent cancers; SIR, standardized incidence ratio; $\mathrm{Cl}$, confidence interval. ${ }^{\mathrm{a}}$ Limited to cancer sites with $>1$ case diagnosed among 300 2-month survivors (2,986 female-years; mean follow-up 9.95 years) of first primary breast-ACC. There was one individual with miscellaneous cancer that is not included in the all solid cancers or all lymphohematopoietic cancers categories.

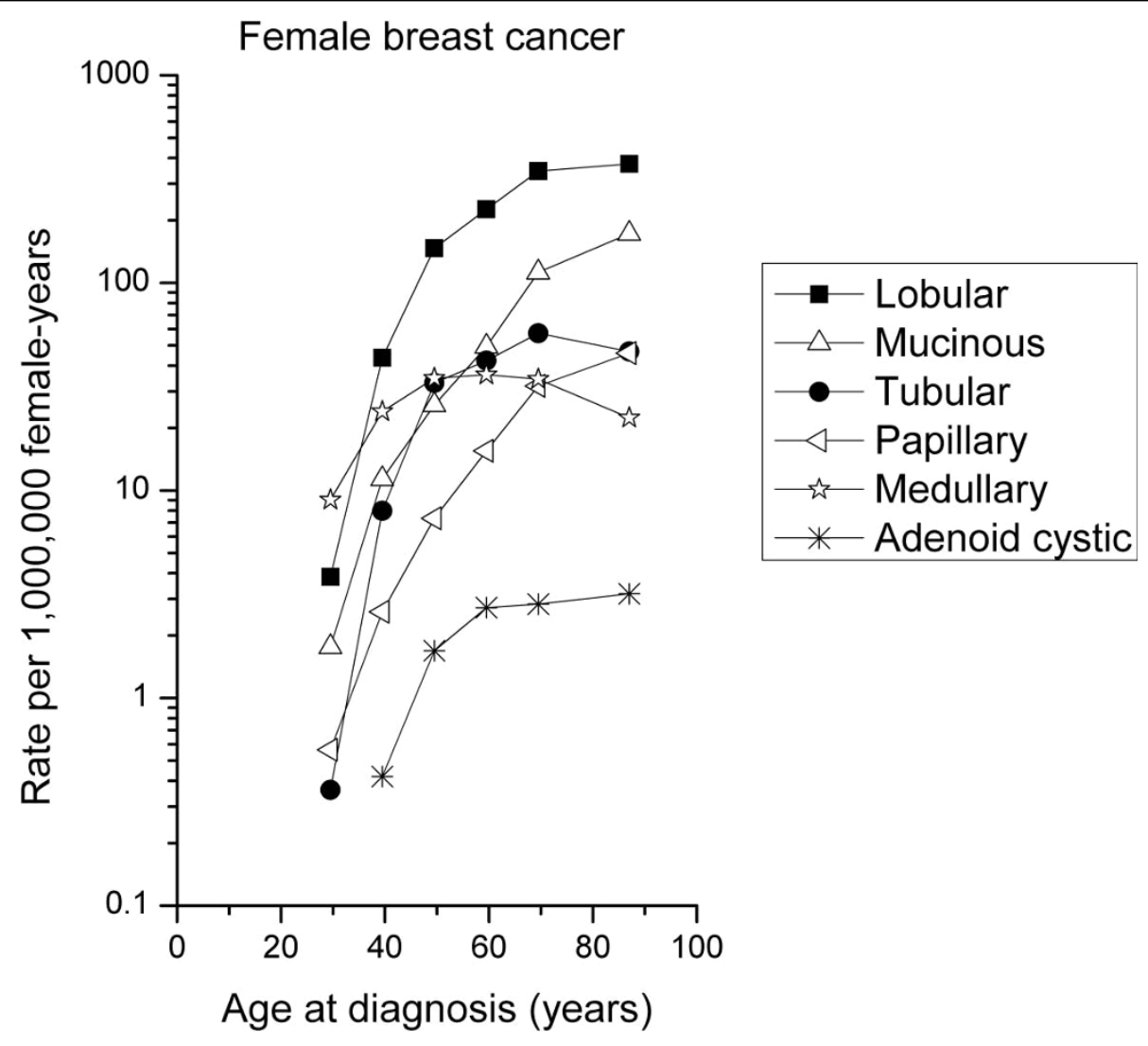

Figure 1 Age-specific incidence rates of special types of female breast carcinomas. Data from the nine cancer registry areas of the Surveillance, Epidemiology and End Results Program, 1977 to 2006. 
age-specific pattern, with IRs increasing rapidly until midlife, followed by a persistent but less steep rise in incidence at older ages.

The overall risk of second-order or higher-order cancers following breast-ACC among females was not increased $(\mathrm{SIR}=1.01,95 \% \mathrm{CI}=0.72$ to 1.38 , observed number of subsequent cancers $=40)($ Table 2$)$. Subsequent risk of all solid tumors did not differ from that expected in the general population $(\mathrm{SIR}=0.94,95 \% \mathrm{CI}$ $=0.65$ to 1.32 , observed number of subsequent cancers $=33$ ), and similarly the risk of any breast cancer was not increased $(\mathrm{SIR}=0.89,95 \% \mathrm{CI}=0.43$ to 1.64 , observed number of subsequent cancers $=10$ ). Based on a small number of cases, the risk of lymphohematopoietic malignancies was nonsignificantly increased after breast-ACC ( $\mathrm{SIR}=1.86,95 \% \mathrm{CI}=0.68$ to 4.05 , observed number of subsequent cancers $=6$ ). No cancers occurred significantly below expectation.

The risk of developing a subsequent breast-ACC following all first cancers and all solid tumors did not differ from that expected in the general population (SIR = 0.86 and 0.91 , respectively), and no cases of breast-ACC were reported following lymphohematopoietic malignancies (Table 3). Following a diagnosis of any first primary breast cancer, risk of breast-ACC was not elevated beyond expectation ( $\mathrm{SIR}=0.71,95 \% \mathrm{CI}=0.28$ to 1.46 ). Colorectal and urinary bladder cancers as well as melanoma were associated with nonsignificantly elevated risks of subsequent breast-ACC.

The overall 5-year relative survival of breast-ACC was $98.1 \%$ with 96 to $97 \%$ relative survival observed across all calendar periods studied (Table 4). Five-year relative survival was excellent among women aged $<50$ years $(94.4 \%)$ and $\geq 50$ years $(99.0 \%)$. Among women diagnosed in 1988 or later without LN involvement, 5-year relative survival was $99.1 \%(n=100)$ and $89.7 \%(n=56)$ among those with tumors $\leq 2 \mathrm{~cm}$ and $>2 \mathrm{~cm}$ tumors, respectively (data not shown). Overall 10-year and 15year relative survival exceeded $90 \%$. Women aged $<50$ and $\geq 50$ years had similar 10 -year relative survival (94.4\%), but slightly lower relative survival was noted at 15 years for older women $(88.9 \%)$ than for younger women (94.3\%).

\section{Discussion}

To date the largest breast-ACC studies $[14,22-25,27,30,32,36,41]$, including one populationbased study [28], have each included fewer than 40 cases, with some studies including cases diagnosed over a $\geq 40$-year time period $[23,24,30]$. With more than 300 incident cases of breast-ACC occurring over a 30-year period, our study is the largest reported to date and is the first to describe incidence, survival, and associated cancers. New population-based information includes the predominance of breast-ACC among females and Whites, with the majority of tumors characterized by ER-negative/PR-negative hormone receptor status, localized stage, and absence of regional LN involvement. Breast-ACC IRs remained stable over the 30 years of study, and relative survival was excellent. In contrast to the $60 \%$ significantly increased risk of contralateral breast cancer following an initial female breast cancer reported in a previous SEER-based study [47], we did not find an increased risk for breast cancer preceding or following breast-ACC. Similarly, no increased risk was observed for all cancers combined or all solid tumors occurring in association with breast-ACC.

Breast-ACC is a rare malignancy, with approximately one case occurring per 1 million female-years. Based on a substantially larger number of cases, we found a similar mean age at diagnosis as previously reported among 14 histologically confirmed breast-ACC cases diagnosed during 1952 to 1982 in the Connecticut Tumor Registry (mean age 64 years) [28]. Some series have similarly

Table 3 Standardized incidence ratios of subsequent breast-ACC among two-month female survivors of other first primary cancers

\begin{tabular}{|c|c|c|c|c|c|}
\hline \multirow[b]{2}{*}{ Site } & \multicolumn{2}{|c|}{ First primary cancer } & \multicolumn{3}{|c|}{ Subsequent breast-ACC } \\
\hline & $n$ & Mean person-years & Obs. & SIR & $95 \% \mathrm{Cl}$ \\
\hline All, excluding nonmelanoma skin & $1,239,815$ & 7.04 & 20 & 0.86 & 0.52 to 1.33 \\
\hline All solid & $1,122,676$ & 7.24 & 20 & 0.91 & 0.56 to 1.41 \\
\hline Colon and rectum & 151,082 & 6.42 & 5 & 1.70 & 0.55 to 3.96 \\
\hline Melanoma, skin & 43,155 & 9.93 & 2 & 2.19 & 0.27 to 7.91 \\
\hline Female breast & 410,448 & 8.58 & 7 & 0.71 & 0.28 to 1.46 \\
\hline Uterine corpus & 90,916 & 10.48 & 2 & 0.69 & 0.08 to 2.48 \\
\hline Urinary bladder & 29,309 & 7.41 & 2 & 2.99 & 0.36 to 10.81 \\
\hline All lymphohematopoietic cancers & 96,222 & 5.80 & 0 & {$[E=$} & \\
\hline
\end{tabular}

Data from the nine cancer registry areas of the Surveillance, Epidemiology and End Results Program, 1977 to 2006 . Except for the general category of all lymphohematopoietic cancers, the table is limited to cancers with $>1$ case of subsequent breast-ACC. Breast-ACC, adenoid cystic carcinoma of the breast; $n$, number of first primary cancers; Obs., observed number of subsequent breast-ACC; SIR, standardized incidence ratio; $\mathrm{Cl}$, confidence interval; $E$, expected number of subsequent breast-ACC. 
Table 4 Relative survival among females diagnosed with adenoid cystic carcinoma of the breast

\begin{tabular}{|c|c|c|c|c|c|c|c|}
\hline \multirow[b]{2}{*}{ Characteristic } & \multirow[b]{2}{*}{$n$} & \multicolumn{2}{|c|}{ 5-year RS } & \multicolumn{2}{|c|}{ 10-year RS } & \multicolumn{2}{|c|}{ 15-year RS } \\
\hline & & $\%$ & $95 \% \mathrm{Cl}$ & $\%$ & $95 \% \mathrm{Cl}$ & $\%$ & $95 \% \mathrm{Cl}$ \\
\hline Total & 285 & 98.1 & $\begin{array}{l}79.9 \text { to } \\
99.8\end{array}$ & 94.9 & $\begin{array}{l}78.9 \text { to } \\
98.8\end{array}$ & 91.4 & $\begin{array}{l}75.0 \text { to } \\
97.2\end{array}$ \\
\hline \multicolumn{8}{|l|}{ Calendar period } \\
\hline $\begin{array}{l}1977 \text { to } \\
1986\end{array}$ & 74 & 96.8 & $\begin{array}{l}63.3 \text { to } \\
99.8\end{array}$ & 95.2 & $\begin{array}{l}67.1 \text { to } \\
99.4\end{array}$ & 95.2 & $\begin{array}{l}67.1 \text { to } \\
99.4\end{array}$ \\
\hline $\begin{array}{l}1987 \text { to } \\
1996\end{array}$ & 109 & 97.2 & $\begin{array}{l}81.4 \text { to } \\
99.6\end{array}$ & 91.0 & $\begin{array}{l}69.7 \text { to } \\
97.6\end{array}$ & 85.0 & $\begin{array}{l}60.7 \text { to } \\
94.9\end{array}$ \\
\hline $\begin{array}{l}1997 \text { to } \\
2005\end{array}$ & 102 & 96.0 & $\begin{array}{l}68.5 \text { to } \\
99.6\end{array}$ & $\sim$ & $\sim$ & $\sim$ & $\sim$ \\
\hline \multicolumn{8}{|l|}{ Age } \\
\hline$<50$ years & 52 & 94.4 & $\begin{array}{l}80.3 \text { to } \\
98.5\end{array}$ & 94.4 & $\begin{array}{l}80.3 \text { to } \\
98.5\end{array}$ & 94.3 & $\begin{array}{l}69.4 \text { to } \\
99.1\end{array}$ \\
\hline$\geq 50$ years & 233 & 99.0 & $\begin{array}{l}6.6 \text { to } \\
100\end{array}$ & 94.4 & $\begin{array}{l}72.8 \text { to } \\
99.0\end{array}$ & 88.9 & $\begin{array}{l}68.9 \text { to } \\
96.3\end{array}$ \\
\hline
\end{tabular}

Data from the nine cancer registry areas of the Surveillance, Epidemiology and End Results Program, 1977 to 2006. Relative survival is based on cases diagnosed during 1977 to 2005 and followed through 2006. n, number of cases; RS, relative survival; $\mathrm{Cl}$, confidence interval; , insufficient follow-up to calculate survival.

reported mean/median ages of 60 to 66 years at diagnosis $[12,22,23,36,42]$, whereas others have described ages that are nearly one decade younger $[17,20,21,24,25$, $32,34,41]$. Breast-ACC often presents with a palpable $[15,17,23-25,32,41]$ and tender $[14,15,23,24,37,48,49]$ mass, which is variably detected on mammography and ultrasound [25,35-37,48,50-52]. Similar to what has been suggested in the literature, we found that tumor size varies widely. Mean tumor sizes of 1.8 to $3.7 \mathrm{~cm}$ have been described $[12,20,21,23,25,32,42]$, and not uncommonly the breast mass is noted to have been present several years prior to diagnosis $[8,25,30,36,41,49,50,53]$. Clinical series report a predominance of centrally located tumors $[14,15,19,25,32,51,52,54]$, nearly equal frequencies of central and upper outer quadrant tumors $[15,27,42]$, or - akin to findings in the SEER Program tumors occurring primarily in the upper outer quadrant $[8,28,34]$.

Supporting findings in previous reports $[15,17-21,27,29,31,35-38,48,50,52,54-57]$, the majority of breast-ACC in the SEER Program was ER-negative/PRnegative; however, hormone receptor-positive tumors have also been described in a minority of cases $[22,23,25,32,34,42,58]$. Although information on HER-2neu is not available in the SEER Program, other series have uniformly reported HER-2-neu-negative status in breast-ACC [18,20,21,23,31,34,37,38,42,50,52,55,56]. Like HER-2-neu negativity, c-kit expression is typically a poor prognostic feature that also characterizes breastACC $[18,21,29,31,34]$ as well as medullary breast cancer, another basal-like breast cancer $[59,60]$. In contrast to what might be expected with ER-negative, PR-negative,
HER-2-neu-negative (triple-negative) breast cancers, the majority of cases of breast-ACC in the SEER Program rarely involved regional $\mathrm{LN}$ and most were associated with excellent survival. These findings support clinical reports that largely $[12,20-25,29,31,32,34-38,41,42,48,50-$ $52,55,56]$, but not exclusively [21-24,34,42,49], describe absence of LN involvement and excellent survival $[22,24,25]$. Metastatic breast-ACC has been rarely reported at initial diagnosis [22], and only one case was observed in the SEER Program over a 30-year period.

The mainstay of therapy for breast-ACC has been surgical excision with or without local radiotherapy, with infrequent use of chemotherapy and hormonal therapy [21-24,38,41,42,52,55]. Single or multiple recurrences may occur years after initial diagnosis $[8,11,13,20,21,23$, $27,32,33,39,40,49]$, and a similar pattern of recurrence has been observed for other triple-negative breast cancers [61].

Similar to the IR pattern previously described for medullary breast cancer, a predominantly ER-negative tumor [26], we found an early-onset incidence pattern for breast-ACC - a rapid rise in incidence at young ages with falling or flattening incidence rates after midlife. Early-onset breast cancer incidence patterns suggest a prominent etiologic role for hormonal influences that occur early in reproductive life [26]. This is, at least in part, a plausible explanation for the markedly higher incidence of breast cancer among females $(I R=132.5$ / 100,000 woman-years) than males $(I R=0.2 / 100,000$ man-years) [62]. In contrast, late-onset incidence patterns - as exemplified by papillary and mucinous breast cancers, typically ER-positive cancers of presumed luminal origin - are characterized by a progressive rise in incidence with advancing age, possibly due to lifelong carcinogenic events and/or exposures [16,26]. Interestingly, papillary carcinomas are among the most common special breast cancer types in males, whereas medullary carcinomas are among the least common [62]. Lobular and tubular breast cancers have age-specific curves that are intermediate between early-onset and late-onset patterns and are postulated to represent a bimodal, mixed population of early-onset and late-onset cancers [26].

The incidence of breast-ACC remained stable during the 30-year study period with no notable rise after the widespread use of mammography beginning in the 1980s. Systematic mammographic screening in the United States has largely resulted in an increase in breast cancer IRs among women $\geq 50$ years of age and in a shift to older age at diagnosis $[63,64]$. Since breast-ACC is characterized by an early-onset age pattern, this may explain, at least in part, why the introduction of mammographic screening has not apparently influenced temporal patterns. In addition, breast-ACC has been reported to be variably detected on mammogram [25,35-37,48,50-52], 
thereby potentially contributing to the lack of rise in IRs with the introduction of mammographic screening. Temporal patterns should also be interpreted in the context of the rarity of breast-ACC, such that the relatively small numbers of cases may have limited our ability to detect significant changes in IRs.

Breast-ACC has been described worldwide but race is rarely specified among reports in the literature $[35,40]$. We found a significantly lower incidence of breast-ACC among Blacks than Whites, which contrasts with the twofold higher incidence of medullary breast cancer described among Blacks compared with Whites $[3,26]$. These findings suggest that racial differences in susceptibility exist within subtypes of basal-like breast cancers.

Synchronous and metachronous in situ and invasive carcinomas have been described in the ipsilateral breast as well as in the contralateral breast in women with breast-ACC [12,14,23-25,31,32,36,42]. Notably, when breast-ACC occurs in conjunction with breast cancer of another histologic subtype, the prognosis is that of the other subtype $[7,12,41]$. Nonbreast cancers - including lymphoma [24], ocular melanoma [25], and cancers of the ovary [28], endometrium [24], supraglottis [24], kidney [24], lung [27], and skin [42] - have been described among patients with breast-ACC. Based on 18 cases of breast-ACC, Millar and colleagues found a subsequent cancer rate of $13 \%, 19 \%$, and $26 \%$ at 5 years, 10 years, and 15 years, respectively [24]. We did not find a significantly increased risk of all cancers combined, or cancers of the breast or other sites prior to or following breastACC when rates were compared with the US general population.

The strengths of our study include the relatively large number of breast-ACC in a population-based setting, which avoids biases inherent to clinical series. Despite the size of our study, however, one limitation is that too few men were diagnosed with breast-ACC to allow calculation of IRs or survival rates. While SEER-9 represents approximately $10 \%$ of the US population, our findings may not be generalizable to women in the entire country nor to other non-US populations, particularly if the racial composition differs. Although we included only microscopically confirmed cases, we did not undertake a pathology review and we cannot exclude the possibility of misclassified cribriform carcinoma, benign collagenous spherulosis, or other entities included in the differential diagnosis of breast-ACC $[7,12,15,20,41,42,65,66]$. Reassuring, however, is that a pathology review of breast-ACC undertaken in the Connecticut Tumor Registry during 1952 to 1982 found $79 \%$ accuracy for cases diagnosed after 1974 in contrast to $23 \%$ accuracy for cases diagnosed prior to 1974 [28].

Another limitation of our study is that information on hormone receptor status was derived from numerous laboratories using different measurement techniques with varying definitions of positive receptor status. Nevertheless, substantial agreement has been reported between centralized laboratory and SEER registry classification for ER-positive/PR-positive and ER-negative/PRnegative breast cancer subtypes [67]. Without a formal pathology review, it is not possible to determine whether the ER-positive and PR-positive breast-ACC cases we observed are misclassified by histology and/or receptor status or represent a true variant of breast-ACC. Notably, hormone receptor-positive breast-ACC has been reported in several clinical series [22,23,25,32,34,42,58]. We were also unable to assess breast-ACC recurrence rates because the SEER Program does not collect information on recurrent disease. Finally, despite the relatively large size of our study, it is possible that significant cancer associations may have gone undetected because of the small absolute number of breastACC cases.

\section{Conclusions}

The present study is the largest of breast-ACC reported to date and the first to describe population-based incidence, survival, and associated cancer patterns. Supporting previous descriptions from clinical series, we found a predominance of breast-ACC among women characterized by ER-negative/PR-negative hormone receptor status, rare regional LN involvement, and excellent survival. An increased risk of breast cancer or other cancers overall was not observed in association with breastACC; however, larger studies will be needed to confirm our findings. Awareness of the favorable clinical behavior of breast-ACC is important, and these findings emphasize the need for clinicians to balance the risks and benefits of cytotoxic therapy given the excellent long-term survival. Future studies may consider pooling cases of breast-ACC to develop additional insight into the molecular pathogenesis, etiology, and best treatment approaches of this rare basal-like breast cancer.

\section{Abbreviations}

ACC: adenoid cystic carcinoma; breast-ACC: adenoid cystic carcinoma of the breast; Cl: confidence interval; ER: estrogen receptor; IR: incidence rate; IRR: incidence rate ratio; LN: lymph node; PR: progesterone receptor; SEER: Surveillance: Epidemiology and End Results; SEER-9: nine cancer registry areas of the Surveillance: Epidemiology and End Results Program; SIR: standardized incidence ratio.

\section{Acknowledgements}

The present work was supported by the Department of Veterans Affairs Medical Center in Oklahoma City, OK, USA (to BG, MMH, GMD) and the Intramural Research Program, Division of Cancer Epidemiology and Genetics, National Cancer Institute, National Institutes of Health, Bethesda, MD, USA (to WFA, REC, JAL, GMD). The sponsors did not directly participate in the study design, data analysis or interpretation, or preparation of the

manuscript. The sponsors approved the submission of the manuscript for publication. 


\section{Author details}

'Department of Veterans Affairs Medical Center, Medical Service (111), 921 NE 13th Street, Oklahoma City, OK 73104, USA. ${ }^{2}$ University of Oklahoma Health Sciences Center, Oklahoma City, OK 73104, USA. ${ }^{3}$ Division of Cancer Epidemiology and Genetics, National Cancer Institute, National Institutes of Health, Department of Health and Human Services, 6120 Executive Blvd, Bethesda, MD 20892, USA.

\section{Authors' contributions}

BG and GMD participated in the conception and design of the study. GMD analyzed the data. All authors participated in interpretation of the data. BG and GMD drafted the manuscript. All authors participated in critical revisions of the manuscript for important intellectual content. All authors approved the final version of the manuscript.

\section{Competing interests}

The authors declare that they have no competing interests.

Received: 15 May 2010 Revised: 11 July 2010 Accepted: 23 July 2010 Published: 23 July 2010

\section{References}

1. Marchio C, Weigelt B, Reis-Filho JS: Adenoid cystic carcinomas of the breast and salivary glands (or 'The strange case of Dr Jekyll and Mr Hyde' of exocrine gland carcinomas). J Clin Pathol 2010, 63:220-228.

2. Kreike B, van Kouwenhove M, Horlings $H$, Weigelt B, Peterse $H$, Bartelink $H$, van de Vijver MJ: Gene expression profiling and histopathological characterization of triple-negative/basal-like breast carcinomas. Breast Cancer Res 2007, 9:R65.

3. Weigelt B, Horlings HM, Kreike B, Hayes MM, Hauptmann M, Wessels LF, de Jong D, Van de Vijver MJ, Van't Veer LJ, Peterse JL: Refinement of breast cancer classification by molecular characterization of histological special types. J Pathol 2008, 216:141-150

4. Billroth T: Die cylindergeschwalst. Untersuchungen ueber die entwicklung der blutgefasse Berlin: G. Reimer 1856.

5. Geschickter CF: Diseases of the Breast: Diagnosis, Pathology, and Treatment Philadelphia, PA: J.B. Lippincott 1945.

6. Azumi N, Battifora $\mathrm{H}$ : The cellular composition of adenoid cystic carcinoma. An immunohistochemical study. Cancer 1987, 60:1589-1598.

7. Bennett AK, Mills SE, Wick MR: Salivary-type neoplasms of the breast and lung. Semin Diagn Pathol 2003, 20:279-304.

8. Elsner B: Adenoid cystic carcinoma of the breast. Review of the literature and clinico-pathologic study of seven patients. Pathol Eur 1970, 5:357-364.

9. Lawrence JB, Mazur MT: Adenoid cystic carcinoma: a comparative pathologic study of tumors in salivary gland, breast, lung, and cervix. Hum Pathol 1982, 13:916-924.

10. Leeming R, Jenkins M, Mendelsohn G: Adenoid cystic carcinoma of the breast. Arch Surg 1992, 127:233-235

11. Nayer HR: Case report section; cylindroma of the breast with pulmonary metastases. Dis Chest 1957, 31:324-327.

12. Peters GN, Wolff M: Adenoid cystic carcinoma of the breast. Report of 11 new cases: review of the literature and discussion of biological behavior. Cancer 1983, 52:680-686.

13. Wilson WB, Spell JP: Adenoid cystic carcinoma of breast: a case with recurrence and regional metastasis. Ann Surg 1967, 166:861-864.

14. Anthony PP, James PD: Adenoid cystic carcinoma of the breast: prevalence, diagnostic criteria, and histogenesis. J Clin Pathol 1975, 28:647-655.

15. Zaloudek C, Oertel YC, Orenstein JM: Adenoid cystic carcinoma of the breast. Am J Clin Pathol 1984, 81:297-307.

16. Sorlie T, Perou CM, Tibshirani R, Aas T, Geisler S, Johnsen H, Hastie T, Eisen MB, van de Rijn M, Jeffrey SS, Thorsen T, Quist H, Matese JC, Brown PO, Botstein D, Eystein Lonning P, Borresen-Dale AL: Gene expression patterns of breast carcinomas distinguish tumor subclasses with clinical implications. Proc Natl Acad Sci USA 2001, 98:10869-10874.

17. Albores-Saavedra J, Heard SC, MCLaren B, Kamino H, Witkiewicz AK: Cylindroma (dermal analog tumor) of the breast: a comparison with cylindroma of the skin and adenoid cystic carcinoma of the breast. Am J Clin Pathol 2005, 123:866-873.
18. Crisi GM, Marconi SA, Makari-Judson G, Goulart RA: Expression of c-kit in adenoid cystic carcinoma of the breast. Am J Clin Pathol 2005, 124:733-739.

19. Pastolero G, Hanna W, Zbieranowski I, Kahn HJ: Proliferative activity and p53 expression in adenoid cystic carcinoma of the breast. Mod Pathol 1996, 9:215-219.

20. Trendell-Smith NJ, Peston D, Shousha S: Adenoid cystic carcinoma of the breast: a tumour commonly devoid of oestrogen receptors and related proteins. Histopathology 1999, 35:241-248.

21. Azoulay S, Lae M, Freneaux P, Merle S, Al Ghuzlan A, Chnecker C, Rosty C, Klijanienko J, Sigal-Zafrani B, Salmon R, Fourquet A, Sastre-Garau X, VincentSalomon A: KIT is highly expressed in adenoid cystic carcinoma of the breast, a basal-like carcinoma associated with a favorable outcome. Mod Pathol 2005, 18:1623-1631.

22. Arpino G, Clark GM, Mohsin S, Bardou VJ, Elledge RM: Adenoid cystic carcinoma of the breast: molecular markers, treatment, and clinical outcome. Cancer 2002, 94:2119-2127.

23. McClenathan JH, de la Roza G: Adenoid cystic breast cancer. Am J Surg 2002, 183:646-649.

24. Millar BA, Kerba M, Youngson B, Lockwood GA, Liu FF: The potential role of breast conservation surgery and adjuvant breast radiation for adenoid cystic carcinoma of the breast. Breast Cancer Res Treat 2004, 87:225-232.

25. Rosen PP: Adenoid cystic carcinoma of the breast. A morphologically heterogeneous neoplasm. Pathol Annu 1989, 24(Pt 2):237-254.

26. Anderson WF, Pfeiffer RM, Dores GM, Sherman ME: Comparison of age distribution patterns for different histopathologic types of breast carcinoma. Cancer Epidemiol Biomarkers Prev 2006, 15:1899-1905.

27. Ro JY, Silva EG, Gallager HS: Adenoid cystic carcinoma of the breast. Hum Pathol 1987, 18:1276-1281.

28. Sumpio BE, Jennings TA, Merino MJ, Sullivan PD: Adenoid cystic carcinoma of the breast. Data from the Connecticut Tumor Registry and a review of the literature. Ann Surg 1987, 205:295-301.

29. Da Silva L, Buck L, Simpson PT, Reid L, McCallum N, Madigan BJ, Lakhani SR Molecular and morphological analysis of adenoid cystic carcinoma of the breast with synchronous tubular adenosis. Virchows Arch 2009, 454:107-114.

30. Galloway JR, Woolner LB, Clagett OT: Adenoid cystic carcinoma of the breast. Surg Gynecol Obstet 1966, 122:1289-1294.

31. Hill PA: c-kit expression in adenoid cystic carcinoma of the breast. Pathology 2004, 36:362-364

32. Kleer $\mathrm{CG}$, Oberman HA: Adenoid cystic carcinoma of the breast: value of histologic grading and proliferative activity. Am J Surg Pathol 1998, 22:569-575.

33. Koller M, Ram Z, Findler G, Lipshitz M: Brain metastasis: a rare manifestation of adenoid cystic carcinoma of the breast. Surg Neurol 1986, 26:470-472.

34. Mastropasqua MG, Maiorano E, Pruneri G, Orvieto E, Mazzarol G, Vento AR, Viale G: Immunoreactivity for c-kit and p63 as an adjunct in the diagnosis of adenoid cystic carcinoma of the breast. Mod Pathol 2005, 18:1277-1282.

35. Okamoto Y, Sumiyama Y, Arima Y, Sakuta M, Okuda T, Noto Y, Naka I, Kiribayashi T, Takahashi K, Kuwajima A: A case of adenoid cystic carcinoma (ACC) of the breast and review of the utility of preoperative imaging diagnose. Breast Cancer 2001, 8:84-89.

36. Santamaria G, Velasco M, Zanon G, Farrus B, Molina R, Sole M, Fernandez PL: Adenoid cystic carcinoma of the breast: mammographic appearance and pathologic correlation. AJR Am J Roentgenol 1998, 171:1679-1683.

37. Sheen-Chen SM, Eng HL, Chen WJ, Cheng YF, Ko SF: Adenoid cystic carcinoma of the breast: truly uncommon or easily overlooked? Anticancer Res 2005, 25:455-458.

38. Soon SR, Yong WS, Ho GH, Wong CY, Ho BC, Tan PH: Adenoid cystic breast carcinoma: a salivary gland-type tumour with excellent prognosis and implications for management. Pathology 2008, 40:413-415.

39. Woyke S, Domagala W, Olszewski W: Fine structure of mammary adenoid cystic carcinoma. Pol Med J 1970, 9:1140-1148.

40. Lim SK, Kovi J, Warner OG: Adenoid cystic carcinoma of breast with metastasis: a case report and review of the literature. J Natl Med Assoc 1979, 71:329-330. 
41. Cavanzo FJ, Taylor HB: Adenoid cystic carcinoma of the breast. An analysis of 21 cases. Cancer 1969, 24:740-745.

42. Shin SJ, Rosen PP: Solid variant of mammary adenoid cystic carcinoma with basaloid features: a study of nine cases. Am J Surg Pathol 2002, 26:413-420.

43. Surveillance Epidemiology and End Results (SEER) Program SEER*Stat Database incidence - SEER 9 Regs Public-Use Nov 2008 Sub (1973-2006) National Cancer Institute DCCPS Surveillance Research Program Cancer Statistics Branch. [http://www.seer.cancer.gov].

44. Fritz A, Percy C, Jack A, Shanmugaratnam K, Sobin L, Parkin DM, Whelan S, (Eds): International Classification of Diseases for Oncology Geneva: World Health Organization, 32000.

45. Devesa SS, Donaldson J, Fears T: Graphical presentation of trends in rates. Am J Epidemiol 1995, 141:300-304.

46. Horner MJ, Ries LAG, Krapcho M, Neyman N, Aminou R, Howlader N, Altekruse SF, Feuer EJ, Huang L, Mariotto A, Miller BA, Lewis DR, Eisner MP, Stinchcomb DG, Edwards BK, (Eds): SEER Cancer Statistics Review, 1975-2006 Bethesda, MD: National Cancer Institute 2009.

47. Curtis RE, Ron E, Hankey BF, Hoover RN: New malignancies following breast cancer. New Malignancies among Cancer Survivors: SEER Cancer Registries, 1973-2000 Bethesda, MD: National Cancer InstituteCurtis RE, Freedman DM, Ron E, Ries LAG, Hacker DG, Edwards BK, Tucker MA, Fraumeni JF Jr 2006, 181-205, NIH Publ. No. 05-5302.

48. Muslimani AA, Ahluwalia MS, Clark CT, Daw HA: Primary adenoid cystic carcinoma of the breast: case report and review of the literature. Int Semin Surg Oncol 2006, 3:17.

49. Verani RR, Van der Bel-Kahn J: Mammary adenoid cystic carcinoma with unusual features. Am J Clin Pathol 1973, 59:653-658.

50. Alis H, Yigitbas H, Kapan S, Kalayci M, Kilic G, Aygun E: Multifocal adenoid cystic carcinoma of the breast: an unusual presentation. Can J Surg 2008, 51:E36-E37.

51. Delanote $S$, Van den Broecke R, Schelfhout VR, Serreyn R: Adenoid cystic carcinoma of the breast in a 19-year-old girl. Breast 2003, 12:75-77.

52. Youk JH, Kim MJ, Kim EK, Lee JY, Oh KK, Park BW: Recurrence of adenoid cystic carcinoma in the breast after lumpectomy and adjuvant therapy. $J$ Ultrasound Med 2006, 25:921-924.

53. Lusted D: Structural and growth patterns of adenoid cystic carcinoma of breast. Am J Clin Pathol 1970, 54:419-425.

54. Sperber F, Blank A, Metser U: Adenoid cystic carcinoma of the breast: mammographic, sonographic, and pathological correlation. Breast J 2002, 8:53-54.

55. Kasagawa T, Suzuki M, Doki T, Fujimori T, Itami M, Takenouchi T, Yamamoto N: Two cases of adenoid cystic carcinoma: preoperative cytological findings were useful in determining treatment strategy. Breast Cancer 2006, 13:112-116.

56. Law YM, Quek ST, Tan PH, Wong SL: Adenoid cystic carcinoma of the breast. Singapore Med J 2009, 50:e8-e11.

57. Torrao MM, da Costa JM, Ferreira E, da Silva MV, Paiva I, Lopes C: Adenoid cystic carcinoma of the breast. Breast J 2007, 13:206.

58. Kern WH: Morphologic and clinical aspects of estrogen receptors in carcinoma of the breast. Surg Gynecol Obstet 1979, 148:240-242.

59. Simon R, Panussis S, Maurer R, Spichtin H, Glatz K, Tapia C, Mirlacher M, Rufle A, Torhorst J, Sauter G: KIT (CD117)-positive breast cancers are infrequent and lack KIT gene mutations. Clin Cancer Res 2004, 10:178-183.

60. Went PT, Dirnhofer S, Bundi M, Mirlacher M, Schraml P, Mangialaio S, Dimitrijevic S, Kononen J, Lugli A, Simon R, Sauter G: Prevalence of KIT expression in human tumors. J Clin Oncol 2004, 22:4514-4522.

61. Kang SP, Martel M, Harris LN: Triple negative breast cancer: current understanding of biology and treatment options. Curr Opin Obstet Gynecol 2008, 20:40-46.

62. Anderson WF, Devesa SS: In situ male breast carcinoma in the Surveillance, Epidemiology, and End Results database of the National Cancer Institute. Cancer 2005, 104:1733-1741.

63. Anderson WF, Reiner AS, Matsuno RK, Pfeiffer RM: Shifting breast cancer trends in the United States. J Clin Oncol 2007, 25:3923-3929.

64. Jatoi I, Anderson WF: Breast cancer overdiagnosis with screening mammography. Arch Intern Med 2009, 169:999-1000, author reply 10001001.

65. Rabban JT, Swain RS, Zaloudek CJ, Chase DR, Chen YY: Immunophenotypic overlap between adenoid cystic carcinoma and collagenous spherulosis of the breast: potential diagnostic pitfalls using myoepithelial markers. Mod Pathol 2006, 19:1351-1357.

66. Rosen PP, Oberman HA: Tumors of the Mammary Gland Washington, DC: Armed Forces Institute of Pathology 1993.

67. Ma H, Wang Y, Sullivan-Halley J, Weiss L, Burkman RT, Simon MS, Malone KE, Strom BL, Ursin G, Marchbanks PA, McDonald JA, Spirtas R, Press MF, Bernstein L: Breast cancer receptor status: do results from a centralized pathology laboratory agree with SEER registry reports? Cancer Epidemiol Biomarkers Prev 2009, 18:2214-2220.

doi:10.1186/bcr2613

Cite this article as: Ghabach et al:: Adenoid cystic carcinoma of the breast in the United States (1977 to 2006): a population-based cohort study. Breast Cancer Research 2010 12:R54.

\section{Submit your next manuscript to BioMed Central and take full advantage of:}

- Convenient online submission

- Thorough peer review

- No space constraints or color figure charges

- Immediate publication on acceptance

- Inclusion in PubMed, CAS, Scopus and Google Scholar

- Research which is freely available for redistribution

Submit your manuscript at www.biomedcentral.com/submit
C) Biomed Central 